\title{
SITIO LAGUNA LAS VEGAS: PROCESAMIENTO Y CONSUMO DE GUANACOS (LAMA GUANICOE) EN LA CUENCA MEDIA DEL RÍO COYLE (PROVINCIA DE SANTA CRUZ)
}

\author{
Luciana Stoessel ${ }^{*}$, Juan Bautista Belardi ${ }^{* *}$ y Flavia Carballo Marina***
}

Fecha de recepción: 17 de noviembre de 2020

Fecha de aceptación: 22 de abril de 2021

\section{RESUMEN}

El sitio Laguna Las Vegas posee una alta integridad y resolución. Es un registro penecontemporáneo formado alrededor de 3050-3210 años AP que se destaca por la alta frecuencia de restos de guanaco (Lama guanicoe) y, en menor magnitud, de cauquén (Chloephaga sp.), acompañados principalmente por machacadores óseos y raspadores de calcedonia. Se postula que el sitio es el resultado del descarte en un campamento formado atricionalmente y en un corto lapso, al que habrían ingresado presas enteras (guanacos) para su procesamiento, consumo y ulterior transporte del esqueleto axial. La presencia de restos de cauquén indica que las ocupaciones humanas habrían tenido lugar, al menos, durante los meses de primavera y verano. Todas estas características lo definen como un sitio novedoso que añade valiosa información sobre el manejo de recursos faunísticos y la movilidad de poblaciones cazadoras-recolectoras en la cuenca media del río Coyle.

Palabras clave: Patagonia austral - cazadores-recolectores - procesamiento - consumoguanaco

\footnotetext{
* INCUAPA-CONICET, Departamento de Arqueología. Facultad de Ciencias Sociales, Universidad Nacional del Centro de la Provincia de Buenos Aires. E-mail: 1stoesse@soc.unicen.edu.ar

** Universidad Nacional de la Patagonia Austral. Unidad Académica Río Gallegos (ICASUR). Laboratorio de Arqueología Dr. Luis A. Borrero. CONICET (CIT Santa Cruz). E-mail: juanbautistabelardi@gmail.com *** Universidad Nacional de la Patagonia Austral. Unidad Académica Río Gallegos (ICASUR). Laboratorio de Arqueología Dr. Luis A. Borrero. CONICET (CIT Santa Cruz). E-mail: flaviacarballomarina@ gmail.com
} 
Relaciones de la Sociedad Argentina de Antropología 46 (1), enero-junio 2021: 339-361

\section{LAGUNA LAS VEGAS SITE: PROCESSING AND CONSUMPTION OF GUANACOS (LAMA GUANICOE) IN THE COYLE RIVER MIDDLE BASIN (SANTA CRUZ PROVINCE)}

\section{ABSTRACT}

Laguna Las Vegas is a high integrity and high resolution site. It is a penecontemporaneous record that was formed around 3050-3210 BP which is remarkable due to the high frequency of guanaco bones (Lama guanicoe) and, to a lesser extent, of cauquén remains (Chloephaga sp.). Additionally, a high frequency of bone pounders and chalcedony scrapers was recorded. We propose that this site was a campsite originated by an attritionally discard behavior within a short time frame, in which whole preys (guanacos) were taken for processing, consumption, and subsequent transport of their axial skeleton. The fact that cauquén remains were found suggests that human occupations took place, at least, during spring and summer. Due to these features, Laguna Las Vegas stands out as a valuable site, one which adds useful information about faunal resource management and mobility of the hunter-gatherer populations of the Coyle River middle basin.

Keywords: Southern Patagonia - hunter-gatherers - processing - consumption - guanaco

\section{INTRODUCCIÓN}

La cuenca del río Coyle se ubica en el sur de la provincia de Santa Cruz (Argentina). Tiene sus cabeceras en cercanía de las estribaciones cordilleranas de las Torres del Paine (Chile) y desemboca en el océano Atlántico formando un gran estuario (Cáceres y Caballero 2006). La ausencia de cotas marcadas junto con la amplitud del valle la convierten en una ruta de menor costo para la circulación de las poblaciones humanas que conecta las vertientes Atlántica y Pacífica (Franco et al. 2019). La información sobre la arqueología de esta cuenca permite avanzar en el conocimiento de la ocupación del sur de Patagonia.

El sitio Laguna Las Vegas (Estancia Rubén Aike) está en la cuenca media del río Coyle, en la estepa arbustiva de mata negra (Junellia tridens) (Oliva et al. 2001) -apenas por encima del fondo de valle (100 m s.n.m.)-, sobre el Brazo Norte del río, en inmediaciones de la confluencia con el Brazo Sur (figuras 1 y 2). La arqueofauna y los artefactos líticos están en superficie y en estratigrafía en depósitos eólicos a cielo abierto. El sitio se encuentra al reparo de los vientos predominantes, sobre la ladera oeste $\left(\leq 5^{\circ}\right)$ de una lomada que enmarca la laguna Las Vegas. El entorno provee pasturas por sobre el promedio del paisaje regional (Mazzoni y Vázquez 2004); la cuenca del río Coyle tiene el mayor número de humedales de toda la provincia de Santa Cruz (Mazzoni y Vázquez 2001). El sitio, además de su cercanía a la confluencia de los brazos del río, se ubica frente a dos grandes cañadones (Corpen Aike y Mayer) a los que se suma el cañadón Camusu Aike (figura 1). La oferta de agua y pasturas se traduce en una alta disponibilidad de guanacos (Lama guanicoe) y aves respecto de las terrazas fluvioglaciares circundantes. Además, en términos regionales, el valle del río Coyle presenta bajo riesgo climático invernal (Borrelli et al. 1997) lo que habría dado mayores posibilidades de ocupación del fondo de valle -tanto por guanacos como por cazadores- durante los meses más fríos.

Con el fin de poner en perspectiva al sitio Laguna Las Vegas, se resume la información arqueológica regional, los lineamientos teóricos relacionados con la selección y el transporte de partes esqueletarias y se presenta la metodología utilizada en el estudio de los materiales arqueológicos. Dada la relevancia del registro arqueofaunístico y, en especial, de los restos de guanaco, el trabajo hará énfasis en ellos, considerando en simultáneo la presencia de restos de cauquén (Chloephaga sp.) y la tecnología ósea y lítica, con el fin de discutir la forma de uso del sitio en el contexto de la arqueología de la cuenca media del río Coyle. Esta información ha sido generada 


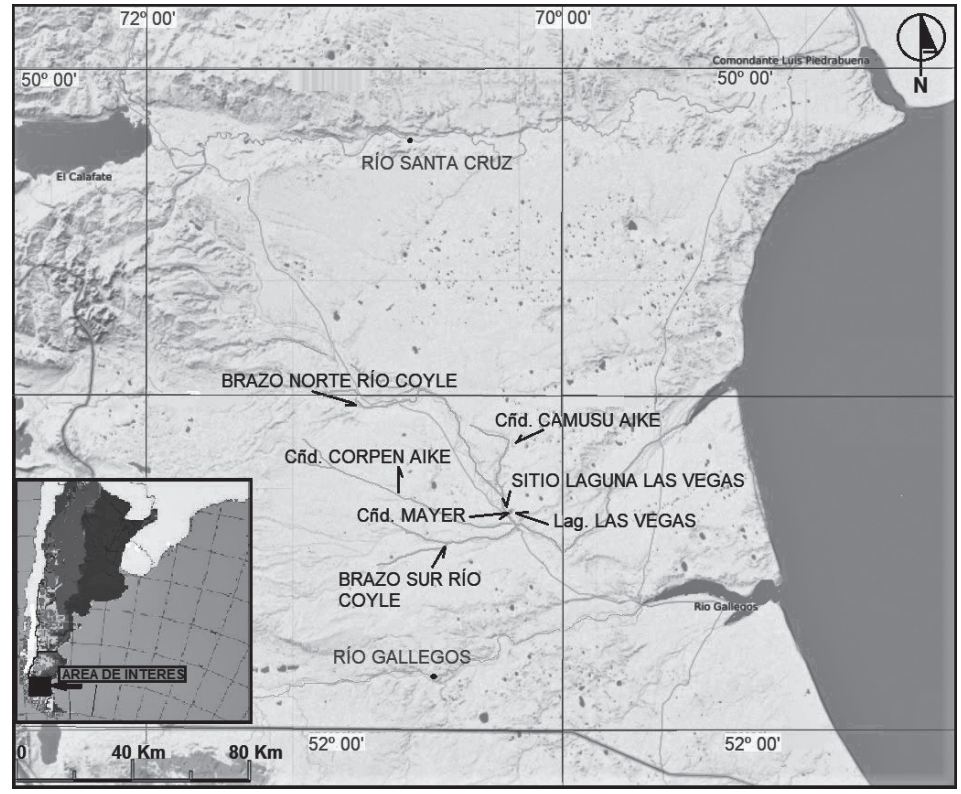

Figura 1. Localización del sitio Laguna Las Vegas

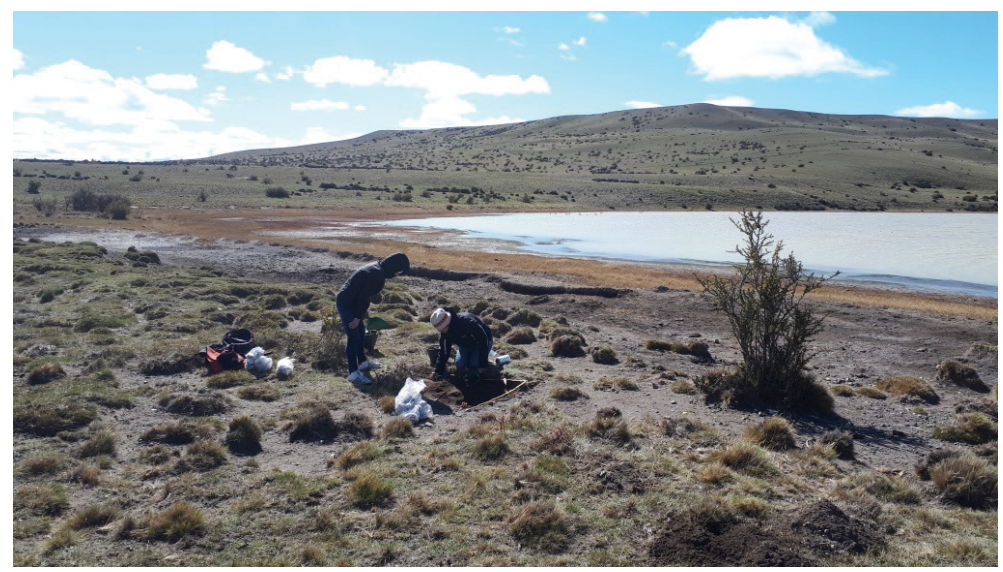

Figura 2. El sitio Laguna Las Vegas y su entorno. Los materiales arqueológicos fueron recuperados en el espacio que se extiende desde donde están las personas hacia la laguna

a lo largo de los últimos 20 años a partir de trabajos de impacto ambiental relacionados con la actividad petrolera (Carballo Marina et al. 2000-02, 2011; Espinosa et al. 2000-02; Belardi et al . 2006, 2021). Si bien se registraron sitios con arqueofaunas como Puesto Peter y Las Horquetas, el momento de su intercepción fue muy tardío, por lo que es muy difícil discriminar entre restos óseos aportados por actividad antrópica y/o los tafonómicos. Por el contrario, el sitio Laguna Las Vegas posee una alta integridad y resolución. Tiene alta frecuencia de individuos de guanaco y de cauquén, de machacadores óseos y raspadores de calcedonia. Estas características hacen que regionalmente sea un sitio novedoso que añade valiosa información al conocimiento del poblamiento cazador-recolector de la cuenca. 


\section{MARCO AMBIENTAL Y ARQUEOLÓGICO REGIONAL}

La laguna Las Vegas se ha formado en un bajo de origen eólico de aproximadamente $1 \mathrm{~km}$ de lado, sobre una terraza fluvial. Tiene régimen pluvionival y marcadas variaciones interanuales (Mazzoni y Vázquez 2001). Los estudios paleoambientales indican que las condiciones actuales en el área se establecen hace $c a$. 4000 años, cuando se instalan las comunidades vegetales de la estepa graminosa (Mancini et al. 2005). La evidencia provista por el estudio de sedimentos de laguna Azul (92 km hacia el sur de Laguna Las Vegas) muestra que entre los 7500 años y 3000 años cal AP hubo condiciones más cálidas y húmedas, indicativas de vientos menos intensos del oeste. Esto es coincidente con los registros obtenidos en la laguna Potrok Aike (67 km al sudoeste de Laguna Las Vegas) (Zolitschka et al. 2019). Luego, durante el Neoglacial (ca. 3000 años cal AP), las temperaturas promedio decrecen de $12,2^{\circ} \mathrm{C}$ a $10,5^{\circ} \mathrm{C}$ (Zolitschka et al. 2019).

En la cuenca media e inferior del río Coyle no hay disponibilidad de cuevas ni de aleros debido a la poca compactación del sedimento Terciario. Solo se los encuentra en las coladas basálticas de las márgenes sur y norte de los ríos Santa Cruz y Gallegos, respectivamente (figura 1). El predominio de la erosión por sobre la depositación genera condiciones de buena visibilidad arqueológica. Esto hizo que se privilegiaran los trabajos distribucionales realizados a partir del reconocimiento de dos unidades de paisaje: Terrazas y Fondo de valles (Carballo Marina et al. 2000-02; Espinosa et al. 2000-02).

El río Coyle dio lugar a un complejo sistema de terrazas con pendientes moderadas a fuertes que se encuentran estabilizadas y cubiertas por depósitos coluviales. La superficie más elevada de la región corresponde a la terraza de entre 190 y 230 m s.n.m., a partir de la cual los sistemas fluviales iniciaron su profundización. En la unidad Terrazas, se tomaron en cuenta las geoformas que se distribuyen de manera homogénea: terrazas, cuencas endorreicas y cañadones. La evidencia arqueológica indica que en ellas se habrían llevado a cabo los mismos tipos de tareas, pero con diferencias en su intensidad, relacionadas con el aprovisionamiento de rocas y actividades de talla. Las mayores densidades artefactuales se concentran en las cuencas endorreicas. Además, se destacan episodios de "talla al paso", que indican el aprovechamiento puntual de un nódulo y que genera una concentración de artefactos, generalmente en superficies no mayores al $\mathrm{m}^{2}$ (Belardi et al. 2006, 2021).

La unidad de paisaje Fondo de valles tiene un relieve suavemente ondulado con médanos y meandros abandonados. En el fondo de los valles que conforman mallines la vegetación es de praderas de tipo higrófila. La evidencia arqueológica muestra conjuntos líticos en sectores denudados del valle, similares a los registrados en terrazas, y a los que se suman artefactos de módulo laminar sobre hojas y restos faunísticos, principalmente guanaco, en conjuntos de baja integridad y resolución (Carballo Marina et al. 2000-02).

La densidad artefactual regional es baja, de orden de magnitud de $10^{-4}$ artefactos por $\mathrm{m}^{2}$, apoyando un uso humano poco intenso del espacio. Se emplearon mayoritariamente rocas locales, tales como dacitas, andesitas y Rocas de Grano Fino Oscuras (RGFO sensu Charlin 2005). Predominan los desechos de talla, núcleos y raederas, que ponen de manifiesto un importante componente expeditivo vinculado con la distribución homogénea y la alta disponibilidad y facilidad de acceso a las rocas.

Se registraron evidencias de interacción del interior con la costa $(\sim 35 \mathrm{~km})$ por la presencia (en baja frecuencia) de moluscos de procedencia atlántica (Nacella magellanica, Mytilus edulis) y del hallazgo de un ejemplar de Panopea abbreviata, cuya distribución actual abarca desde Río de Janeiro (Brasil) hasta la localidad de Puerto Deseado (norte de la provincia de Santa Cruz). Junto con los moluscos, las bajas frecuencias de artefactos de rocas alóctonas (obsidana negra y gris verdosa veteada) se relacionarían con circuitos de circulación de bienes e información con poblaciones localizadas principalmente al norte, al oeste y al este de la región (Carballo Marina 
et al. 2000-02; Belardi et al. 2006). El diseño predominante de puntas de proyectil corresponde al Magallanes IV (Holoceno medio y tardío). Estas particularidades, asemejan a la cuenca media del río Coyle con la cuenca superior del río Santa Cruz y a la de los ríos Gallegos y Chico (Espinosa et al. 2020).

Los primeros fechados radiocarbónicos obtenidos en la cuenca media del río Coyle sitúan las ocupaciones cazadoras recolectoras en momentos históricos. Los restos humanos de un individuo femenino ubicado en la localidad de Las Horquetas (Brazo Sur del río Coyle), a $7 \mathrm{~km}$ al sur del sitio Laguna Las Vegas, fueron datados en torno a 200 años AP y su análisis isotópico sugiere que su dieta era continental (Barberena 2002). En la confluencia de los cañadones del Baile y Camusu Aike, se recuperaron en estratigrafía huesos de caballo (Equus caballus) que fueron datados como modernos, espacialmente relacionados con lo que se interpretó como un campamento Tehuelche-Aonikenk (Carballo Marina et al. 2000-02). Otros dos fechados se obtuvieron sobre un hueso de guanaco en la confluencia del cañadón Puesto Peter y el Brazo Norte del río Coyle (304 \pm 44 años AP -AA-86452), y un diente humano en Estancia El Zorro (tomado de un cráneo recuperado durante la construcción de un pozo de agua) (305+46 años AP; AA-86451) (Carballo Marina et al. 2011). Las crónicas también dan cuenta de otras ocupaciones en tiempos históricos (Peláez y Jiménez 2006). En el sitio Las Horquetas, ubicado en la base de una terraza y próximo al individuo femenino, se dató un hueso de guanaco en 1660 60 años AP (AA-47339) (Belardi et al. 2006). En las cabeceras del río Coyle (Fuentes del Coyle), se lograron fechados radiocarbónicos que van desde 8856 \pm 84 años AP (AA-91424) hasta el Holoceno tardío (Borrero et al. 2006; Borrero y Borrazzo 2011). El reciente hallazgo de una punta tipo cola de pescado inmediatamente al sur de la localidad de La Esperanza (cuenca media del río) es concordante con una cronología temprana (ver figuras 4 y 6 en Matera et al. 2019).

El paisaje arqueológico de la cuenca media del río Coyle se ajusta al generado por una alta movilidad residencial, lo que concuerda con la distribución relativamente homogénea de recursos (agua, guanacos y materias primas líticas). El espacio habría tenido una baja intensidad de uso, en función de la circulación de poblaciones humanas hacia y entre las cuencas de los ríos Santa Cruz y Gallegos. Esto se modificó con la incorporación del caballo hacia fines del siglo XVII y la consecuente reducción de la movilidad residencial (Goñi 2000). El confinamiento en reservas como la de Camusu Aike -sitios Campo Indio 1002, Cañadón del Baile y laguna Puesto Peterrompe los patrones de movilidad y afecta la continuidad social y biológica de las poblaciones cazadoras-recolectoras (Belardi et al. 2006, 2013, 2021; Nuevo Delaunay et al. 2017).

\section{LASELECCIÓN, EL TRANSPORTEY EL PROCESAMIENTODEPARTES ESQUELETARIAS}

El manejo de las presas por parte de grupos cazadores-recolectores puede ser dividido en distintas etapas: obtención, procesamiento, selección de unidades anatómicas y transporte. El trabajo pionero de L. Binford (2012 [1978]) sobre el caribú (Rangifer tarandus) desarrolla una familia de curvas (estrategias) a partir de la utilidad económica de las distintas partes esqueletarias (gourmet, global, gourmet-global y no sesgada) que resultan de las evaluaciones de transporte hechas por los cazadores bajo distintas contingencias. Estudios posteriores mostraron que el tamaño del animal cazado, el producto que se desea obtener (e.g., carne, grasa ósea, médula, cueros), el número de cazadores participantes, la tecnología disponible y la distancia entre el sitio de caza y el campamento residencial también inciden en los costos implicados en el procesamiento y transporte de las carcasas (entre otros, Bunn et al. 1988; O'Connell et al. 1988; Lyman 1991; Lupo 2006). Todos estos aspectos han tenido su evaluación y discusión en Patagonia (entre otros, Borrero et al. 1985; Muñoz 1997, 2001; Mengoni Goñalons 1999; De Nigris 2004, 2008; Fernández 2010; Rindel et al. 2017) y condujeron al desarrollo de diferentes índices de utilidad económica apli- 
cados al guanaco: el de carne (Borrero 1990), el de cavidad medular (Mengoni Goñalons 1996) y el de médula insaturada (Morín 2007). Este último expande la aplicación del índice de médula y, si bien los valores no se obtuvieron directamente sobre huesos de guanaco, la alta correlación encontrada con respecto al índice desarrollado para caribú permitió su aplicación a casos patagónicos (Rindel 2013). Ambos índices de médula complementan el trabajo de Enloe (1993) sobre fragmentos diafisiarios: aquellos relativamente largos y de similar tamaño se asociarían a fracturas estandarizadas y al procesamiento especializado de médula ósea. Lo contrario es sugerido por fragmentos de menor longitud y variabilidad en tamaños que serían propios de una explotación ocasional. Por último, el índice de secado de carne (De Nigris y Mengoni Goñalons 2004) hace foco sobre el consumo diferido del esqueleto axial.

El trabajo de Emerson (1993) fue realizado desde una perspectiva general que comprende las curvas desarrolladas por Binford. Su planteo señala que las limitaciones de transporte son los factores más importantes que determinan el conjunto que se lleva al campamento base, pudiéndose implementar dos estrategias: una de Máxima Explotación (Maximum Carcass Recovery strategies) en la que se seleccionarán carcasas completas y otra de Explotación Limitada (Limitated Carcass Recovery strategies), en la que se eligen las partes de mayor rendimiento económico. Existen dos factores que pueden influir en las decisiones de transporte: el rendimiento de grasa esqueletaria de las unidades anatómicas y los costos de procesamiento. Los elementos del esqueleto axial tienen en general bajo rendimiento de grasa, no así las unidades apendiculares. En consecuencia, bajo una estrategia de Explotación limitada se priorizará el transporte de estas últimas. Sucederá lo contrario si la variable que determina la selección de unidades anatómicas es el costo de procesamiento. En este caso, los elementos axiales requieren mayor energía y tiempo para su procesamiento, por lo que serán transportados.

El costo del transporte también es considerado una variable crítica en el modelo de lugar central (Central Place model) (entre otros, Broughton 1999), porque afecta el grado de procesamiento en el campo. Así, a medida que la tasa de encuentro de presas disminuya, dicho costo se incrementará ya que la distancia al campamento será mayor. En consecuencia, es esperable que se maximice el transporte de partes de alta utilidad al campamento base dejando de lado aquellas de baja utilidad en el sitio de caza (entre otros, Barlow y Metcalfe 1996). Sobre esta base, se puede plantear la predicción contraria: si la tasa de encuentro de presas es alta, los costos de transporte disminuyen y así también la selectividad de partes esqueletarias. Todo lo reseñado puede enmarcarse en lo registrado entre grupos Hadza quienes "may be maximizing the amounts of animal products transported to central places by making trade-offs between field processing and transport costs that minimize product waste" (Lupo 2006:48). En suma, los conjuntos arqueológicos responden a "the actors' evaluations of differing contingencies in different situations" (Binford 2012 [1978]:81).

\section{METODOLOGÍA}

Los materiales arqueológicos -óseos y líticos- fueron recuperados en trabajos de campo llevados a cabo en los años 2016 y 2019. La exposición de materiales en superficie por el decapitado de la cubierta edáfica mostró que la distribución abarca -al menos- un área de $27 \mathrm{~m}$ en sentido N-S por $8 \mathrm{~m}$ en sentido E-O (figuras 2 y 3 ).

En el sector de mayor frecuencia de restos se planteó un eje transversal en sentido O-E de 8 $\mathrm{m}$ de longitud, subdividido en cuadrículas de $1 \mathrm{~m}^{2}$ a cada lado de este (figura 3 ). A esto se sumó una cuadrícula de $1 \mathrm{~m}^{2}$ a la altura del metro 5 Sur, a $3 \mathrm{~m}$ del eje transversal. De esa forma, se relevaron $17 \mathrm{~m}^{2}$ en los que se recolectó todo el material arqueológico superficial. Además, sobre la base de la presencia de una alta frecuencia de restos óseos en superfice (tabla 1), se excavó una 
cuadrícula (metro 1 Norte) para determinar la potencia del conjunto $(-32 \mathrm{~cm})$ y datar el inicio de la depositación. El material de superficie y el de la excavación fue analizado de manera conjunta.

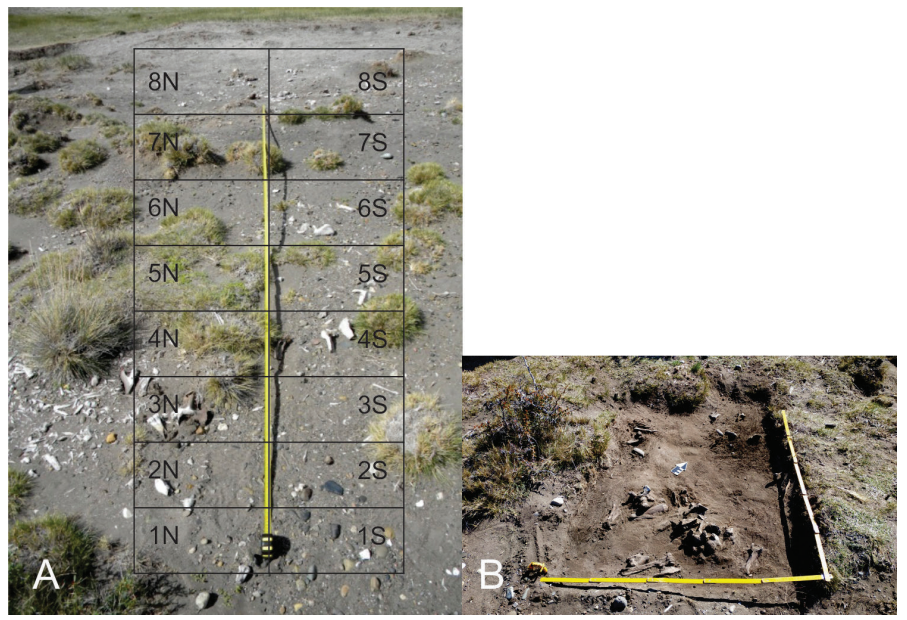

Figura 3. A. Detalle del eje central de la recolección de materiales arqueológicos y localización de las cuadrículas ( $\mathrm{N}=$ norte, $\mathrm{S}=$ sur). B. Detalle de la excavación de la cuadrícula 1 Norte

Como se mencionara, el análisis arqueofaunístico se centralizó sobre el guanaco. Se realizaron determinaciones y análisis cuantitativos (medidas de abundancia taxonómica: NISP, MNI; medidas de abundancia anatómica: MNE, MAU, MAU\%). Para evaluar la representación anatómica del conjunto se consideró el MNE estandarizado de acuerdo a las regiones anatómicas definidas por Stiner (1991) y modificadas por Muñoz (1997): 1) cabeza, 2) esqueleto axial y pelvis, 3) miembro delantero superior, 4) miembro delantero inferior, 5) miembro trasero superior, 6) miembro trasero inferior, y 7) autopodio. La completitud anatómica del conjunto se calculó mediante el índice tMNE/MNI (a mayor valor del índice mayor la completitud anatómica). Además, se empleó el índice que compara la representación de cabeza y miembros y el grado de fragmentación del conjunto fue determinado a partir del cálculo de los indices NISP/MNEt, NISP/MNEAxial y NISP/ MNEApendicular. Con el fin de ponderar económicamente el perfil esqueletario se utilizaron los índices de carne (Borrero 1990), el de cavidad medular (Mengoni 1996) y el de grasa insaturada (Rindel 2013). Estos dos últimos refuerzan el análisis de la longitud de los fragmentos diafisiarios (Enloe 1993). Luego, para evaluar el transporte y el consumo diferido, se empleó el índice de secado de carne (De Nigris y Mengoni Goñalons 2004). Para conocer acerca de la estructura social de las presas y la estacionalidad de caza se buscó determinar el sexo de los individuos a partir de las variables no métricas de la pelvis (Kaufmann et al. 2013) y las categorías etarias según los criterios de fusión de los elementos óseos (Kaufmann 2009).

Con el fin de evaluar la integridad del sitio se llevaron a cabo análisis tafonómicos sobre la totalidad de los restos de guanaco. Se correlacionó el MAU\% con los índices de densidad mineral (Elkin 1995) y se consideraron las proporciones entre las epífisis del húmero y del radiocúbito (Binford 2012 [1978]) y la de astillas/epífisis de húmero, radiocúbito, fémur y tibia (Belardi et al. 2012). Se evaluó la incidencia de la meteorización (Behrensmeyer 1978), la acción de raíces (Behrensmeyer 1978; Montalvo 2002) y de roedores (Binford 1981; Bocek 1986), la actividad de carnívoros (Binford 1981), la depositación de carbonato de calcio y óxido de manganeso (Gutiérrez 2004) y el deterioro químico (Gutiérrez 2004), la abrasión y el pisoteo (Olsen y Shipman 1988).

Para evaluar los efectos de la acción humana se analizaron fracturas (Johnson 1985; Enloe 1993), huellas de corte (Binford 1981; Lyman 2005) y alteraciones térmicas (Benett 1999). Para el 
estudio de las fracturas se tomó en cuenta su tipo y rasgos tecnológicos asociados (Johnson 1985), con especial interés en la identificación de aquellos rasgos diagnósticos de marcado perimetral y su relación con la manufactura de machacadores óseos (Hajduk y Lezcano 2005; Santiago et al. 2019). En las huellas de corte se consideró: morfología, orientación y distribución (Binford 1981).

En el estudio de los materiales líticos se identificaron, sobre base macroscópica, las materias primas empleadas y se siguieron los tipos artefactuales definidos por C. Aschero (1975 rev. 1983). Se contabilizaron los desechos de talla con talón y los artefactos formatizados.

\section{RESULTADOS}

En la recolección efectuada en el año 2016, seis de las ocho cuadrículas tenían materiales concentrados en los extremos del sitio (cuadrículas metro 1 Norte y Sur y cuadrículas metro 5 Sur, metro 6 Norte y Sur y metro 7 Norte y Sur). En la recolección del año 2019 se puedo ver que la concentración ósea se correspondía con el inicio del relevamiento en la cuadrícula metro 1, que es la que se encuentra en una cota superior, seguida por la cuadrícula metro 5. Lo señalado se explicaría porque los depósitos eólicos que contienen al sitio se están exponiendo por erosión desde las cotas inferiores. Además, en las cuadrículas más cercanas a la laguna (metros 6-8) solo se recuperó material en la primera recolección. Estos aspectos sugieren que el material se encontraba en estratigrafía -y aún se encuentra- en el caso de las cotas superiores, tal como lo muestra la presencia de una alta frecuencia de restos óseos y líticos en la excavación de la cuadrícula metro 1 Norte, que a la vez no difieren del conjunto de superficie.

Tabla 1. Frecuencia de restos óseos y líticos por cuadrícula (metros 1-8)

\begin{tabular}{|c|c|c|c|c|c|c|}
\hline \multirow{2}{*}{$\begin{array}{c}\text { Cuadrículas } \\
(\text { metros 1-8) }\end{array}$} & \multicolumn{3}{|c|}{ Norte } & \multicolumn{3}{c|}{ Sur } \\
\cline { 2 - 7 } & Óseo & Lítico & Total & Óseo & Lítico & Total \\
\hline 1 & 144 & 2 & 146 & 17 & 9 & 26 \\
\hline 2 & 8 & 3 & 11 & 21 & 1 & 22 \\
\hline 3 & 30 & 6 & 36 & 8 & 2 & 10 \\
\hline 4 & - & - & - & 9 & 4 & 13 \\
\hline 5 & 21 & 5 & 26 & 47 & 10 & 57 \\
\hline \multirow{2}{*}{5} & 37 & 3 & 40 & 44 & 2 & 15 \\
\hline 6 & 21 & - & 21 & 22 & - & 22 \\
\hline 7 & - & - & - & 16 & 7 & 23 \\
\hline 8 & 261 & 19 & 280 & 197 & 36 & 233 \\
\hline Total & & & & & &
\end{tabular}

Para evaluar la potencial variabilidad cronológica del sitio se realizaron dos fechados radiocarbónicos sobre restos de fémures de guanacos con huellas culturales recuperados en extremos del relevamiento de superficie, cuadrículas metro 1 Norte y metro 6 Sur, respectivamente. Las dataciones obtenidas fueron de 3050 \pm 90 años AP (2938-3436 cal AP; LP-3647) y 3210 140 años AP (2971-3814 cal AP; LP-3618) ${ }^{1}$ (Belardi et al. 2021), lo que permite plantear la penecontemporaneidad de la depositación de los restos arqueológicos. A la vez, dan cuenta de una mayor profundidad temporal para la cuenca media del río Coyle.

El conjunto arqueofaunístico está conformado por un total de 458 restos. El 72,70\% (n=333) corresponde a guanaco, el 23,14\% (n=106) a la categoría artiodáctila, el 3,27\% (n=15) a cauquén, 
el $0,65 \%(n=3)$ a ave indeterminada y el $0,2 \%$ a roedores $(n=1)$. El cálculo del MNI permitió estimar la presencia de 15 individuos de guanaco entre los que se identificaron 10 adultos, cuatro subadultos (uno $\leq 30$ meses y tres $\leq$ de 36 meses) y un juvenil ( $\leq 19$ meses). Entre los adultos se pudo determinar, a partir de características no métricas de la pelvis (Kaufmann et al. 2013), la presencia de al menos una hembra. Sobre este perfil etario no se puede establecer la estacionalidad de uso del sitio.

Se recuperaron restos de cauquén con evidencias de consumo. En el conjunto están representados cinco individuos, cuatro adultos y un juvenil. Esta es un ave migratoria que anida en Patagonia austral, principalmente en ambientes productivos ligados a mallines como los presentes en la cuenca del río Coyle. Su época de cría se extiende desde fines de septiembre hasta fines de abril, con un pico de nacimientos a mediados de noviembre. En abril se dirige hacia el norte de Patagonia y el sur de la provincia de Buenos Aires (Cossa 2019 y citas allí presentes). Por lo tanto, la presencia de restos de cauquén, entre los que se encuentra representado un juvenil, permitó vincular a las ocupaciones humanas con el periodo primavera-verano.

El guanaco está representado por especímenes correspondientes a todas las regiones del esqueleto (tabla 2). Las extremidades son las más frecuentes, principalmente el miembro delantero inferior seguido del trasero superior y delantero superior. El segmento axial y los huesos correspondientes al autopodio son los de menor frecuencia (tabla 2, figuras 4 y 5). Esta representación diferencial de partes esqueletarias está sustentada tanto por el índice tMNE/MNI $(9,35)$, que muestra un bajo grado de completitud de las carcasas, como así también por el que compara la representación de los elementos de la cabeza y de los miembros $(0,15)$. El valor obtenido del índice NISP/MNEt $(1,83)$ indica que el conjunto tiene un bajo grado de fragmentación. Asimismo, los índices NISP/MNEAxial $(4,34)$ y NISP/MNEApendicular $(4,09)$ muestran valores similares, lo que sugiere que no existió una fragmentación diferencial de ambos segmentos del esqueleto.

Tabla 2. Medidas de abundancia esqueletaria

\begin{tabular}{|l|c|c|c|c|c|}
\hline \multicolumn{1}{|c|}{ Unidades anatómicas } & NISP & MNI & MNE & MAU & MAU\% \\
\hline Bulla timpánica & 9 & 4 & 8 & 4 & 40 \\
\hline Maxilar & 2 & 1 & 2 & 2 & 20 \\
\hline Mandíbula & 8 & 2 & 2 & 2 & 20 \\
\hline Atlas & 2 & 2 & 2 & 2 & 20 \\
\hline Axis & 5 & 5 & 5 & 5 & 50 \\
\hline Vértebra cervical & 18 & 4 & 16 & 3,2 & 32 \\
\hline Vértebra torácica & 23 & 3 & 19 & 1,58 & 15,8 \\
\hline Vértebra lumbar & 14 & 3 & 13 & 1,85 & 18,5 \\
\hline Sacro & 5 & 5 & 5 & 5 & 50 \\
\hline Costilla & 8 & 1 & 4 & 0,16 & 1,6 \\
\hline Escápula & 2 & 2 & 2 & 1 & 10 \\
\hline Húmero Px. & 19 & 13 & 18 & 9 & 90 \\
\hline Húmero Diáf. & 7 & 2 & 2 & 1 & 10 \\
\hline Húmero Ds. & 17 & 11 & 17 & 8,5 & 85 \\
\hline Radiocúbito Px. & 23 & 13 & 20 & 10 & 100 \\
\hline Radiocúbito Diáf. & 4 & 1 & 1 & 0,5 & 5 \\
\hline
\end{tabular}


(Tabla 2. Continuación)

\begin{tabular}{|l|c|c|c|c|c|}
\hline \multicolumn{1}{|c|}{ Unidades anatómicas } & NISP & MNI & MNE & MAU & MAU\% \\
\hline Radiocúbito Ds. & 7 & 3 & 6 & 3 & 30 \\
\hline Metacarpo Px. & 4 & 3 & 4 & 2 & 20 \\
\hline Metacarpo Diáf. & 1 & 1 & 1 & 0,5 & 5 \\
\hline Hemipelvis & 4 & 2 & 3 & 1,5 & 15 \\
\hline Fémur Px. & 10 & 4 & 6 & 3 & 30 \\
\hline Fémur Diáf. & 4 & 1 & 1 & 0,5 & 5 \\
\hline Fémur Ds. & 21 & 15 & 20 & 10 & 100 \\
\hline Rótula & 1 & 1 & 1 & 0,5 & 5 \\
\hline Tibia Px. & 14 & 9 & 13 & 6,5 & 65 \\
\hline Tibia Diáf. & 7 & 1 & 3 & 1,5 & 15 \\
\hline Tibia Ds. & 4 & 4 & 4 & 2 & 20 \\
\hline Metatarso Px. & 10 & 5 & 10 & 5 & 50 \\
\hline Metapodio Diáf. & 5 & 1 & 1 & 0,25 & 2,5 \\
\hline Metapodio Ds. & 10 & 3 & 9 & 4,5 & 45 \\
\hline Calcáneo & 3 & 2 & 3 & 1,5 & 15 \\
\hline Astrágalo & 3 & 3 & 3 & 1,5 & 15 \\
\hline Unciforme & 2 & 1 & 2 & 1 & 10 \\
\hline Cuneiforme & 1 & 1 & 1 & 0,5 & 5 \\
\hline Cuboide & 1 & 1 & 1 & 0,5 & 5 \\
\hline Lunar & 1 & 1 & 1 & 0,5 & 5 \\
\hline Escafoide & 1 & 1 & 1 & 0,5 & 5 \\
\hline Navicular & 1 & 1 & 1 & 0,12 & 1,2 \\
\hline Entocuneiforme & 1 & 1 & 0,5 & 5 \\
\hline $1^{\circ}$ falange & 1 & 6 & 0,75 & 7,5 \\
\hline $2^{\circ}$ falange & 1 & & & \\
\hline
\end{tabular}

Referencias: Px., proximal; Ds., distal; Diáf., diáfisis

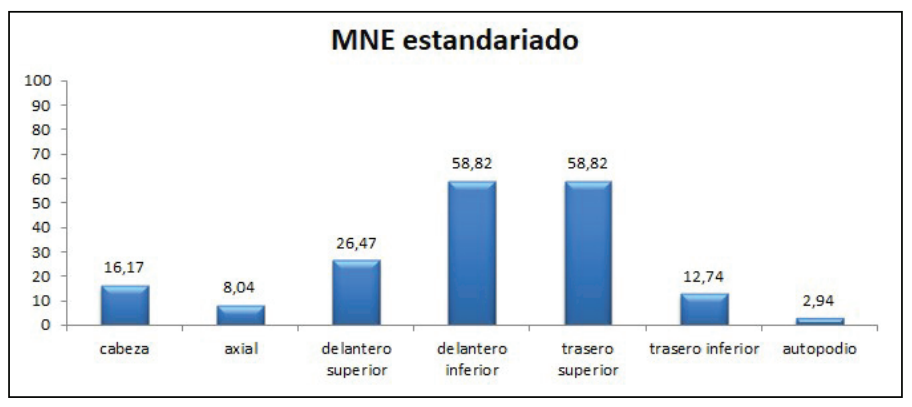

Figura 4. Representación anatómica del conjunto de restos de guanaco 


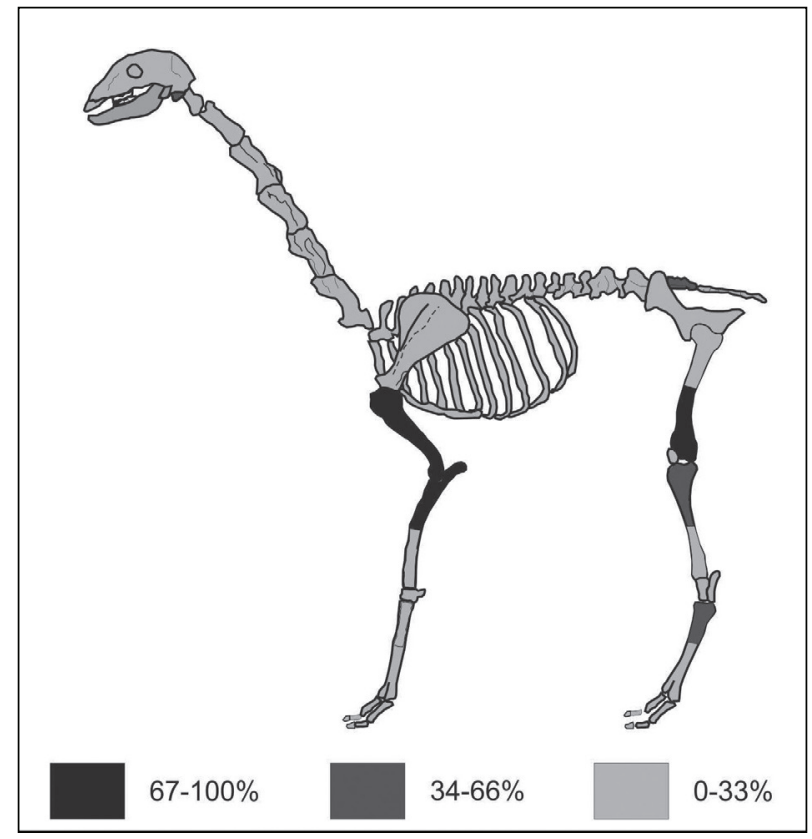

Figura 5. MAU\% de guanaco

\section{Consideraciones tafonómicas}

Trabajos arqueológicos previos en la cuenca media del río Coyle generaron expectativas tafonómicas sobre la preservación del registro arqueológico y su potencial contaminación por depositaciones actuales (Belardi y Carballo Marina 2003). En las terrazas, las posibilidades de enterramiento son bajas y los restos óseos están expuestos a procesos de meteorización intensos que generan su destrucción. Por esto, con el transcurso del tiempo, en los sitios arqueológicos solo perdurarán los materiales líticos. En la unidad de paisaje Fondo de valles existe mayor posibilidad de enterramiento, lo cual favorece la preservación de los materiales. Esto también genera la posible contaminación de contextos arqueológicos con huesos depositados naturalmente. En esta unidad, los procesos característicos se corresponden con la acción de las raíces y depositaciones químicas, vinculadas con las características del sustrato (e.g., mayor humedad) y la mayor cobertura vegetal.

La densidad mineral ósea no habría influido en la representación de especímenes (Spearman's $r s=-0,20524 ; \mathrm{p}=0,22983)$. Esto también se evidencia en las proporciones en la que se encuentran representadas la epífisis proximal $(52,77 \%)$ y la distal $(47,22 \%)$ del húmero y la proximal (75\%) y distal $(25 \%)$ del radiocúbito (datos tomados de tabla 2). Si bien hay una desproporción en las representaciones de epífisis de ambos huesos, predominan las de menor densidad mineral.

Por otra parte, la alta densidad de restos de guanaco no se relacionaría con eventos de muerte por estrés invernal (Belardi y Rindel 2008), ya que no están representadas todas las partes esqueletarias esperadas de acuerdo al número mínimo de individuos, estas se encuentran fragmentadas y su disposición carece de orden anatómico. Tampoco la lluvia tafonómica explicaría las características del conjunto ni la concentración en un lugar que no exhibe diferencias topográficas con los alrededores.

Las principales modificaciones identificadas en el conjunto fueron las marcas de raíces, que condicen con el enterramiento somero de los materiales (tabla 3, figura 6). El 33,17\% de los restos presenta meteorización entre los estadios 2 y 4 y corresponden a las porciones expuestas 
de los elementos. El 58,73\% carece de esta modificación (figura 6), entre los que se incluyen los especímenes de la excavación. Además, se registraron depositaciones de carbonato -esperable en un ecosistema lagunar-en el $27 \%$ de los restos, que podrían dificultar la identificación de otro tipo de modificaciones potenciales (e.g., huellas de corte). Las restantes variables fueron observadas en muy baja frecuencia (tabla 3 ).

Tabla 3. Variables tafonómicas registradas en el conjunto de guanaco

\begin{tabular}{|l|c|c|}
\hline Variables tafonómicas & NISP & NISP\% \\
\hline Raíces & 198 & 43,23 \\
\hline Meteorización & 189 & 41,26 \\
\hline Carbonato & 122 & 26,63 \\
\hline Roedores & 11 & 2,4 \\
\hline Manganeso & 10 & 2,18 \\
\hline Abrasión & 4 & 0,87 \\
\hline Pisoteo & 2 & 0,43 \\
\hline Deterioro químico & 1 & 0,21 \\
\hline
\end{tabular}

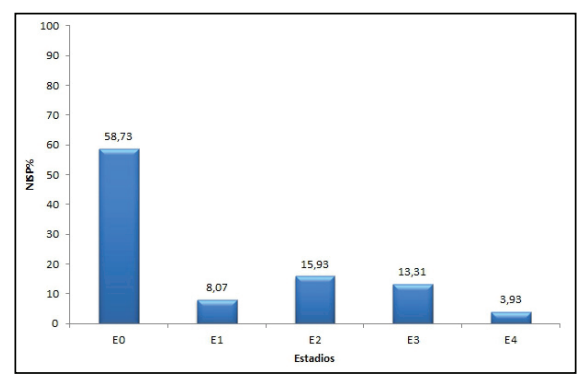

Figura 6. Estadios de meteorización registrados en el conjunto de guanaco

El conjunto arqueofaunísitico del sitio Laguna Las Vegas condice con las expectativas tafonómicas generadas para la unidad de paisaje Fondo de valles (Belardi y Carballo Marina 2003). El rápido enterramiento de los restos fue lo que permitió su conservación, favorecida por una matríz de $\mathrm{pH}$ alcalino $(9,38)$. Por otra parte, la presencia de restos de cauquén sustenta la buena preservación del sitio, ya que se espera que sus huesos perduren menos tiempo que los de guanaco (Cruz 2015). En suma, el conjunto posee una alta integridad y resolución.

\section{Procesamiento antrópico}

El resultado de la correlación del MAU\% y el MGUI de guanaco (Borrero 1990) indica que la representación de partes esqueletarias no estaría vinculada con su rendimiento (Spearman's $r s=0,35125 ; \mathrm{p}=0,057008)$. Sin embargo, la correlación entre el MAU\% y el índice de secado de carne (De Nigris y Mengoni Goñalons 2004) fue significativa (Spearman's $r s=-0,60339$; $\mathrm{p}=$ 0,013338), lo que indicaría que aquellas partes esqueletarias más propicias para el secado están menos representadas. Se identificaron $44(13,21 \%)$ especímenes de guanaco con huellas de corte, 
correspondientes tanto al esqueleto axial $(n=15)$ como apendicular $(n=29)$. La localización de las huellas indica que corresponden principalmente a actividades de fileteo $(n=42) y$, en muy baja frecuencia, a desarticulación ( $\mathrm{n}=2$; figura 7 ).

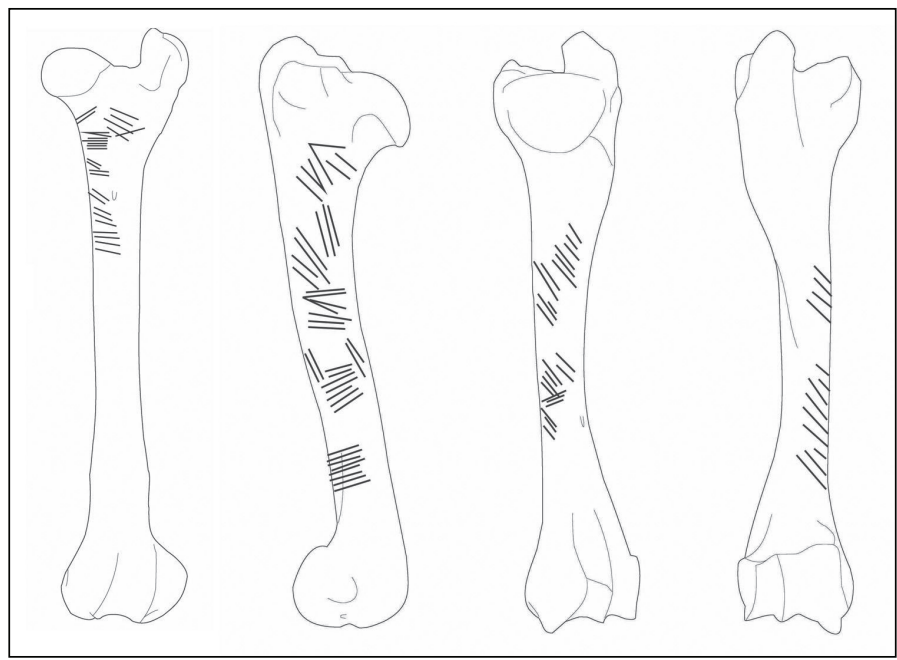

Figura 7. Resumen de la localización de huellas en fémur y húmero de guanaco

Las evidencias de fracturas antrópicas en huesos largos (puntos de impacto $n=26$, negativos de lascados $=80)$ en su mayoría se corresponden con marcado perimetral $(n=28)$ y se asocian con machacadores óseos (Hajduk y Lezcano 2005; Santiago et al. 2019). Fueron confeccionados en fémur, húmero y radiocúbito de guanaco (tabla 4 y figura $8 \mathrm{~A}, \mathrm{~B}$ y C) y se distribuyen de manera relativamente uniforme a lo largo de las cuadrículas. La mayoría $(n=19)$ posee una circunferencia incompleta que no se debería a la fractura por uso como machacador, sino a la realizada para fracturar el hueso. Por lo tanto, la fractura es anterior a la confección del instrumento. Así, se aprovechó el borde remanente de la circunferencia del elemento óseo en la que se observan negativos de lascados laterales (figura $8 \mathrm{~B}$ ). Ocho presentan marcado perimetral completo y se identificó un machacador manufacturado sobre un cilindro óseo de fémur con claras fracturas previas (figura $8 \mathrm{C}$ ).

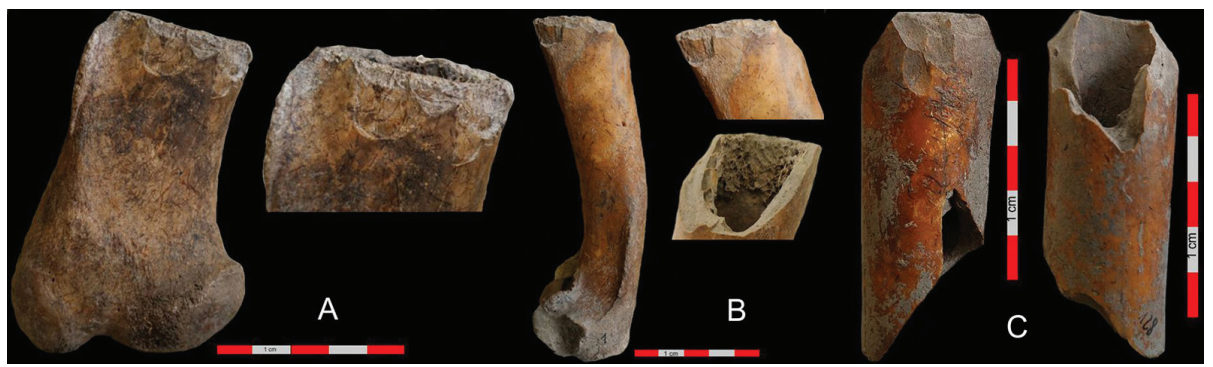

Figura 8. A. Machacador con circunferencia completa (húmero). B. Machacador con circunferencia incompleta (húmero). C. Machacador manufacturado sobre un cilindro óseo (fémur) 
Relaciones de la Sociedad Argentina de Antropología 46 (1), enero-junio 2021: 339-361

Tabla 4. Soportes y características de las circunferencias de los machacadores

\begin{tabular}{|c|c|c|c|c|c|c|}
\hline \multirow{2}{*}{ Machacadores } & \multicolumn{2}{|c|}{ Fémur } & \multicolumn{2}{c|}{ Húmero } & \multicolumn{2}{c|}{ Radiocúbito } \\
\cline { 2 - 7 } & Ep. Px. & Ep. Dist. & Ep. Px. & Ep. Dist. & Ep. Px. & Ep. Dist. \\
\hline $\begin{array}{c}\text { Circunferencia } \\
\text { completa }\end{array}$ & 1 & 4 & 2 & 1 & - & - \\
\hline $\begin{array}{c}\text { Circunferencia } \\
\text { incompleta }\end{array}$ & 6 & 5 & 2 & 4 & 2 & - \\
\hline Cilindro óseo & \multicolumn{2}{|c|}{1} & \multicolumn{3}{|c|}{-} & \multicolumn{2}{c|}{} \\
\hline
\end{tabular}

Referencias: Ep.: epífisis; Px.: proximal; Dist.: distal.

En menor frecuencia se reconocieron fracturas transversales que presentan bordes irregulares y abradidos $(n=18)$, lo que podría sugerir un origen postdepositacional. No obstante, algunos de estos especímenes presentan negativos de lascados laterales por lo cual no se descarta un origen antrópico y la posterior modificación por diversos procesos (e.g., meteorización). Además, se recuperaron diez desechos de fractura helicoidal y se relevaron nueve fracturas longitudinales asociadas a puntos de impacto y negativos de lascado. La alteración térmica solo está presente en dos especímenes y en un grado bajo.

Para el análisis del aprovechamiento de la médula ósea se consideró la totalidad de los fragmentos de diáfisis recuperados $(\mathrm{n}=67)$. La mayoría son relativamente largos (mayores a $4 \mathrm{~cm}$ ), con un predominio de aquellos entre 50-80 mm $(\mathrm{n}=35)$ y $110-130 \mathrm{~mm}(\mathrm{n}=12)$. Los tamaños, sumado a la escasa variabilidad en la longitud, sugieren una estandarización en las fracturas vinculadas a la producción de médula ósea. Asimismo, la correlación con el índice de cavidad medular (Mengoni Goñalons 1996) fue no significativa (Spearman's $r s=0,52179 ; \mathrm{p}=0,3)$, lo cual condice con estos resultados. No obstante, sí se registró una correlación significativa con el índice de médula no saturada (Spearman's rs=0,80144; p=0,0009879; Rindel 2013). Con respecto a la explotación de otros nutrientes, como la grasa ósea, no se recuperaron fragmentos de tejido esponjoso que pudieran indicar su consumo (Outram 2001; Bourlot 2010). La presencia de las epífisis completas de los huesos largos, así como la escasa fragmentación de los elementos axiales sugiere que este recurso no habría sido explotado.

\section{Características generales del conjunto lítico}

Se recuperaron 55 artefactos enteros (41 desechos de talla y 14 formatizados), manufacturados principalmente sobre calcedonia y RGFO, y 19 desechos de talla fracturados sin talón (tabla 5). Todas las materias primas identificadas son de proveniencia local y están disponibles en los bordes de lagunas y en las terrazas circundantes. Sin embargo, la calcedonía parece tener una distribución más restringida (Belardi et al. 2006; Carballo Marina et al. 2011), por lo que también se destaca el registro de cinco nódulos chicos, de entre 20 y $45 \mathrm{~mm}$.

Hay lascas corticales $(35 \%)$ en todas las materias primas. Entre los desechos de talla son mayoría los de longitudes entre 11 y $40 \mathrm{~mm}$ (75,75\%), seguidos por aquellos entre 41 y $57,5 \mathrm{~mm}$ $(18,18 \%)$. Solo dos desechos se encuentran en el intervalo 1-10 mm.

Predominan los raspadores en calcedonia $(\mathrm{N}=8)$ y sus módulos se ajustan a las longitudes de los nódulos mencionados, ya que oscilan entre 21,4 y $41 \mathrm{~mm}$. El raspador mas largo tiene $57,5 \mathrm{~mm}$ y fue confeccionado en RGFO, al igual que dos de las raederas, que son dobles y están fracturadas. La otra raedera es simple, de dacita, y es el artefacto de mayor longitud (110 mm). Los percutores de andesita tienen $81 \mathrm{~mm}$ y $92 \mathrm{~mm}$ de largo y el restante, 73,5 $\mathrm{mm}$. 


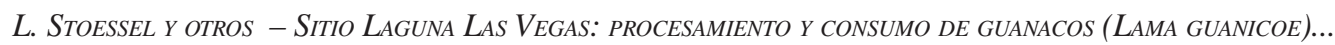

Tabla 5. Tipos artefactuales discriminados por materia prima lítica (además se recuperaron 19 desechos de talla sin talón: nueve en RGFO, cinco en dacita, tres en madera silicificada y dos en calcedonia)

\begin{tabular}{|l|c|c|c|c|c|c|c|}
\hline \multicolumn{1}{|c|}{$\begin{array}{c}\text { Tipo } \\
\text { artefactual }\end{array}$} & Calcedonia & RGFO & Dacita & $\begin{array}{c}\text { Madera } \\
\text { silicificada }\end{array}$ & Andesita & Indet. & TOTAL \\
\hline Lasca primaria & 2 & - & 1 & 1 & 2 & - & 6 \\
\hline Lasca secundaria & 1 & 2 & 3 & - & - & - & 6 \\
\hline Lasca de dorso & 1 & - & - & - & 1 & - & 2 \\
\hline Lasca angular & 5 & 6 & 3 & 5 & 1 & 4 & 24 \\
\hline Lasca plana & - & - & - & - & 1 & - & 1 \\
\hline $\begin{array}{l}\text { Lasca de } \\
\text { reducción } \\
\text { bifacial }\end{array}$ & - & - & 1 & - & - & - & 1 \\
\hline Chunk & - & - & - & - & - & 1 & 1 \\
\hline Raspador & 5 & 1 & & 2 & - & - & 8 \\
\hline Raedera & - & 2 & 1 & - & - & - & 3 \\
\hline Percutor & - & - & - & - & 2 & 1 & 3 \\
\hline TOTAL & 14 & 11 & 9 & 8 & 7 & 6 & 55 \\
\hline
\end{tabular}

Referencias: RGFO: roca de grano fino oscura; Indet.: indeterminada.

\section{DISCUSIÓN Y CONCLUSIONES}

Laguna Las Vegas es un sitio al aire libre ubicado sobre el lado oeste de la laguna que aprovecha el reparo brindado por una suave lomada. Presenta un muy buen estado de preservación vinculado con el entierro rápido de los materiales arqueológicos en sedimentos éolicos alcalinos. Esto, junto con la penecontemporaneidad de la depositación de restos óseos y líticos en torno a los 3200 años AP resulta en su alta integridad y resolución. En la región, se destaca por el conjunto arqueofaunístico: alta frecuencia de restos de guanaco correspondientes a 10 adultos de ambos sexos, cuatro subadultos y un juvenil, y cinco individuos de cauquén, entre ellos un juvenil. La presencia de esta ave indica que el sitio se habría formado, al menos, durante primavera-verano, y en momentos finales de condiciones regionales más cálidas y húmedas, inmediatamente anteriores al inicio del Neoglaciar (Zolitschka et al. 2019) y ya instaladas las comunidades vegetales actuales (Mancini et al. 2005).

El entorno del sitio Laguna Las Vegas, de bajo riesgo climático invernal (Borrelli et al. 1997), está caracterizado por la disponibilidad de agua y pasturas provistas por los mallines del fondo de valle de los brazos Norte y Sur del río Coyle y los cañadones tributarios. Esto se traduce en una alta oferta local de guanacos y consecuentemente en espacios de caza en torno al sitio. Así, las distancias implicadas en el transporte de las presas habrían sido cortas. En el caso del guanaco -100-120 kg- puede sostenerse que no se necesitarían más de cuatro cazadores adultos para transportarlo entero. Bajo este escenario se esperaría el ingreso al sitio de presas completas o con un escaso procesamiento.

Si bien el perfil de partes esqueletarias muestra todas las regiones del esqueleto, predominan los miembros delanteros y traseros (tabla 2, figuras 4 y 5). No se observa correlación entre las partes esqueletarias y su rendimiento económico, tanto con respecto a la carne como al conteni- 
do de médula, y tampoco se ve un claro ajuste con alguna de las curvas propuestas por Binford (2012 [1978]) ni con las estrategias de Emerson (1993). No obstante, sí se obtuvo una correlación significativa con el índice de médula insaturada. Entonces, ¿bajo qué condiciones de uso humano del espacio se habría formado el sitio Laguna Las Vegas? ¿A qué situación respondería un MNI de guanacos tan alto, espacialmente concentrado, penecontemporáneo y con un perfil esqueletario donde predominan los miembros delanteros y traseros?

Se podría pensar en un caso de caza comunal-masiva, pero la distribución relativamente homogénea del guanaco, un contexto poblacional de baja densidad (Belardi et al. 2006, 2021), la baja representación del esqueleto axial y la ausencia de puntas de proyectil y bolas (Borrero 2013) llevan a proponer otro escenario: uno generado por eventos de caza atricional realizados por distintas partidas de caza articuladas desde el sitio (lugar central) en un corto lapso. Con respecto a las partes esqueletarias, su perfil se correspondería con aquellas que fueron consumidas y abandonadas producto del procesamiento de presas que habrían ingresado mayoritariamente enteras al sitio. La falta de coherencia anatómica concuerda con el desarrollo de actividades de descarte, donde los huesos de alto rinde en carne, médula y grasa fueron procesados y consumidos. Las huellas de corte indican que se llevaron a cabo actividades de descarne y desarticulación. El análisis de los fragmentos diafisiarios, así como de los patrones de fractura y las altas frecuencias de lascados y puntos de impacto apuntan hacia el procesamiento sistemático para el consumo de médula ósea, lo que explicaría la baja frecuencia de estos fragmentos, descartando así la acción de procesos tafonómicos (Belardi et al. 2012). El predominio de fracturas transversales asociadas con el marcado perimetral, además de permitir obtener formas base para la manufactura de machacadores, se relacionaría con la extracción de médula. La correlación significativa entre las partes esqueletarias y el índice de médula insaturada sugiere que se procesaron principalmente para el consumo inmediato aquellas unidades anatómicas ricas en este nutriente. No obstante, no se observa la explotación de la grasa del tejido trabecular ya que mayoritariamente se recuperaron las epífisis completas y hay una baja fragmentación de los especímenes axiales. Ahora bien, si las presas entraron enteras, ¿por qué está tan poco representado el esqueleto axial? La primera posibilidad es que este segmento se encuentre en otra área aún no identificada del sitio. Así y todo, el conjunto estudiado tiene elementos axiales, no hay coherencia anatómica entre los distintos restos y presenta una alta frecuencia de machacadores, lo que sugiere el descarte integral y sin segregación espacial de los elementos consumidos y de los artefactos líticos empleados para procesar. Otra posibilidad es que la mayor parte del esqueleto axial se haya procesado para su ulterior transporte. En situaciones donde se decide maximizar el traslado del producto animal es esperable el descarne y abandono de aquellas unidades anatómicas que poseen menor producto remanente y que requieren poco tiempo de procesamiento (miembros delanteros y traseros) y el transporte de aquellos elementos de mayores rindes económicos (axiales) y cuyos costos de procesamiento son más altos (O’Connell et al. 1988; Emerson 1993). Esta estrategia condice con el consumo diferido de carne dado que los elementos axiales son los más ricos en músculos y los más propicios para ser secados (De Nigris y Mengoni Goñalons 2004). Esta propuesta está sustentada sobre la correlación positiva con el índice de secado. A la vez, la baja frecuencia de los elementos del autopodio y las falanges indicaría el transporte mayoritario de los cueros fuera del sitio. Entonces, el procesamiento de las presas es escalonado, ya que segrega temporal y espacialmente las carcasas.

Un patrón similar de representación de partes esqueletarias ha sido registrado en otros sitios del interior de Patagonia, como por ejemplo en Cerro de los Indios 1. Aquí predominan los huesos de las extremidades, seguidos por las cinturas, el cráneo y, en muy baja frecuencia, costillas y vértebras. El patrón fue atribuido a la selección de aquellas unidades anatómicas ricas en médula y al consumo diferido de partes (De Nigris 2008).

La elevada frecuencia de machacadores $(\mathrm{N}=28)$ podría estar vinculada con la preparación de pemmican, tal lo sugerido por Hajduk y Lezcano (2005) y Santiago et al. (2019). Lo señala- 
do, tiene sentido si se consideran los problemas que trae aparejado el invierno en ambientes de media-alta latitud (Hosfield 2016:634-635) -aún en sectores de menor riesgo invernal-y si, además, no hay disponibilidad de abrigos rocosos, como en la cuenca del río Coyle. Su preparación en un contexto de alta disponibilidad de presas también podría responder al marco general del procesamiento para el transporte.

El conjunto artefactual lítico se ajusta a lo propuesto acerca del papel central del procesamiento de guanacos a partir de la alta frecuencia de raspadores $(\mathrm{N}=8)$ y la presencia de raederas $(\mathrm{N}=3)$. Los percutores y las lascas corticales junto con los tamaños de los desechos de talla, indican la realización de parte de las primeras etapas de reducción de nódulos y núcleos de acotadas dimensiones.

El uso cazador-recolector del sitio Laguna Las Vegas debe ponderarse en el contexto regional de la cuenca media del río Coyle. Es el primer sitio que brinda una clara asociación de arqueofaunas con materiales líticos. La evaluación de la variabilidad de los conjuntos arqueológicos, tanto en la unidad de paisaje Fondo de valles como en Terrazas, se centralizó en la diversidad de artefactos líticos y en las rocas empleadas en su manufactura (Belardi et al. 2021). En los sitios de momentos históricos también se utilizó la forma de la distribución y la frecuencia de raspadores de vidrio (Belardi et al. 2013; Nuevo Delaunay et al. 2017). Además de la evidencia arqueofaunística se destaca el uso de la calcedonia y la alta frecuencia de raspadores. Esta roca había sido registrada con importantes frecuencias en solo dos sitios: Laguna McCall (Belardi et al. 2006), lindante con el cañadón Camusu Aike (a unos $62 \mathrm{~km}$ al norte), y en El Chiripá (a unos $70 \mathrm{~km}$ al noroeste), sobre el brazo norte del río Coyle (Carballo Marina et al. 2011), aunque en este último caso se informó como ópalo. Laguna Las Vegas reforzaría la idea inicial de un uso oportunista y puntual de la calcedonia, ya que la disponibilidad regional de rocas de buena calidad para la talla daría cuenta de su baja circulación regional. Por otra parte, dado el reconocimiento de que al sur del río Santa Cruz predominan las raederas (Orquera 1987), la presencia mayoritaria de raspadores acompaña lo inusual del sitio.

En suma, el sitio Laguna Las Vegas muestra una situación diferente a lo conocido para la cuenca media del río Coyle. Permite ampliar la interpretación funcional de conjuntos de arqueofaunas de guanaco (sitios Puesto Peter y Las Horquetas), añade el caso del aprovechamiento del cauquén en la estepa, y provee evidencia para discutir aspectos como el transporte y el procesamiento de presas. En este sentido, sugiere un componente logístico en un paisaje donde habría predominado la movilidad residencial (Binford 1981). Por ultimo, el sitio también brinda información novedosa sobre contextos de procesamiento al aire libre en el sur de Patagonia continental. La ampliación de las excavaciones permitirán no solo la evaluación de las ideas propuestas, sino también la formulación de nuevos planteos vinculados con la ocupación cazadora-recolectora de la cuenca media del río Coyle.

\section{AGRADECIMIENTOS}

A la familia Arbilla (Ea. Rubén Aike) por permitirnos trabajar en su campo y al Sr. Juan Agüero (Ea. Las Horquetas) por su colaboración. Alejandro Súnico nos informó de la concentración de huesos de guanaco y Pablo Binaghi nos ayudó en los relevamientos. Luis Borrero, Gustavo Martínez y Matías Medina leyeron y comentaron el manuscrito, ayudando a ajustar y desarrollar ideas. Isabel Cruz, Mónica Grosso Bravo y Juan Pablo Escalada atendieron gentilmente nuestras consultas. Al Lic. Pedro Tiberi por la realización del mapa del área de estudio. A los dos evaluadores anónimos cuyos certeros comentarios y sugerencias contribuyeron a aclarar distintos aspectos del trabajo.

A la UNPA por brindar las facilidades para que la investigación pudiera llevarse a cabo. 


\section{NOTAS}

1 Las dataciones fueron calibradas usando el programa CALIB 8.2 (Stuiver et al. 2021) y la curva de calibración para el hemisferio sur SHCal20 (Hogg et al. 2020) considerando dos sigmas. También se envió a datar una muestra del inicio de la depositación de huesos obtenida en la excavación, pero problemas técnicos en el LATyR y el contexto de pandemia por Covid 19 impidieron contar con esta información.

\section{BIBLIOGRAFÍA}

Aschero, C.

1975. revisión (1983). Ensayo para una clasificación morfológica de artefactos líticos. Ms.

Barberena, R.

2002. Los límites del mar. Isótopos estables en Patagonia meridional. Colección Tesis de Licenciatura. Buenos Aires, Sociedad Argentina de Antropología.

Barlow, K. R. y D. Metcalfe

1996. Plant utility indices: Two Great Basin examples. Journal of Archaeological Science 23: 351-371.

Behrensmeyer, A.

1978. Taphonomic and Ecologic Information from Bone Weathering. Paleobiology 4 (2): 150-162.

Belardi, J. B. y F. Carballo Marina

2003. Tafonomía regional en la cuenca media del río Coyle (Santa Cruz, Patagonia, Argentina). Intersecciones en Antropología (4): 59-73.

Belardi, J. B., F. Carballo Marina y S. Espinosa

2006. Cazadores-recolectores en la cuenca media e inferior del río Coyle. En J. B. Belardi, F. Carballo Marina y S. Espinosa (eds.), La cuenca del río Coyle: estado actual de las investigaciones: 97-126. Río Gallegos, Universidad Nacional de la Patagonia Austral.

Belardi, J. B., F. Carballo Marina, A. Nuevo Delaunay y H. De Angelis

2013. Raspadores de vidrio y de gres cerámico en la Reserva Tehuelche (Aonikenk) de Camusu Aike: aportes al conocimiento de poblaciones indígenas de los siglos XIX y XX en el territorio de Santa Cruz. Relaciones de la Sociedad Argentina de Antropología XXXVIII (1): 37-57.

Belardi, J. B., F. Carballo Marina y J. L. Sáenz

2021. Hunter-gatherers in a broad landscape: off site regional archaeology in the Coyle River basin, Southern Patagonia (Argentina). En M. Bonomo y S. Archila (eds.), South American Contributions to World Archaeology, One World Archaeology series. Cham, Suiza, Springer-Nature. En prensa.

Belardi, J. B. y D. Rindel

2008. Taphonomic and acrchaeological aspects of massive mortality processes in guanaco (Lama guanicoe) caused by Winter stress in Southern Patagonia. Quaternary International 180 (1): 38-51.

Belardi, J. B., D. Rindel y T. J. Bourlot

2012. Much more than it was expected: preservational differences of diaphysis and epiphyseal ends of guanaco (Lama guanicoe) long bones in Southern Patagonia (Argentina). Journal of Taphonomy 10 (1): 45-65.

Benett, J. L. 1999. Thermal Alteration of Buried Bone. Journal of Archaeological Science 26: 1-8. 
L. Stoessel y otros - Sitio Laguna Las Vegas: procesamiento y Consumo de guanacos (LAMA Guanicoe)...

Binford, L.

1981. Bones: Ancient Men and Modern Myths. New York, Academic Press.

2012 [1978]. Nunamiut ethnoarchaeology. New York, Percheron Press.

Bocek, B.

1986. Rodent Ecology and Burrowing Behavior: Predicted Effects on Archaeological Site Formation. American Antiquity 51(3): 589-603.

Borrelli, P., G. Oliva, M. Williams, L. González, P. Rial y L. Montes

1997. Sistema regional de soporte de decisiones. Santa Cruz y Tierra del Fuego. Río Gallegos: Prodesar -INTA-GTZ- EEA Santa Cruz.

Borrero, L. A.

1990. Fuego-Patagonian bone assemblages and the problem of comunal guanaco hunting. En L. B. Davis

y B. O. K. Reeves (eds.), Hunters of the recent Past: 373-399. London, Unwin Hyman.

2013. Estrategias de caza en Fuego-Patagonia. Comechingonia. Revista de Arqueología 17(1): 11-26.

Borrero, L. A. y K. Borrazo

2011. La geografía cultural del sudoeste de Patagonia Continental. En L. A. Borrero y K. Borrazo (comps.), Bosques, Montañas y cazadores: investigaciones arqueológicas en Patagonia Meridional: 7-36. Buenos Aires, CONICET-IMHICIHU.

Borrero, L. A., M. Casiraghi y H. D. Yacobaccio 1985. First Guanaco-Processing Site in Southern South America. Current Anthropology 26(2): 273-276.

Borrero, L. A., N. V. Franco, F. M. Martin, R. Barberena, R. Guichón, J. B. Belardi, C. Favier Dubois y G. L. L'Heureux

2006. Las cabeceras del Coyle: información arqueológica y circulación de poblaciones humanas. En J.

B. Belardi, F. Carballo Marina y S. Espinosa (eds.), La cuenca del río Coyle. Estado actual de las investigaciones: 75-95. Río Gallegos, Universidad Nacional de la Patagonia Austral.

Bourlot, T.

2010. Zooarqueología de sitios a cielo abierto en el Lago Cardiel (Patagonia, Argentina): fragmentación ósea y consumo de grasa animal en grupos cazadores-recolectores del Holoceno tardío. Oxford, Archaeopress.

Broughton, J. M.

1999. Resource Depression and Intensification during the Late Holocene, San Francisco Bay: Evidence from Emeryville Shellmound Vertebrate Fauna. Berkeley, University of California Press.

Bunn, H. T., L. E. Bartram y E. M. Kroll

1988. Variability in Bone Assemblage Formation from Hadza Hunting, Scavenging, and Carcass Processing. Journal of Anthropological Archaeology 7: 412-457.

Cáceres, A. P. y J. O. Caballero

2006. Consideraciones generales sobre la cuenca del río Coyle o Coig. En J. B. Belardi, F. Carballo Marina y S. Espinosa (eds.), La cuenca del río Coyle. Estado actual de las investigaciones: 21-28. Río Gallegos, Universidad Nacional de la Patagonia Austral.

Carballo Marina, F., J. B. Belardi, S. Espinosa y B. Ercolano 2000-02. Tecnología y movilidad en el río Coyle, Santa Cruz. Cuadernos del Instituto Nacional de Antropología y Pensamiento Latinoamericano 19: 89-107. 
Carballo Marina, F., J. B. Belardi y J. L. Sáenz

2011. Distribución espacial del registro arqueológico en la unidad de paisaje terrazas, cuenca media del río Coyle (provincia de Santa Cruz, Argentina). Magallania 39 (2): 207-222.

Charlin, J.

2005. Aprovisionamiento de materias primas líticas en el campo volcánico de Pali Aike (Santa Cruz): una primera aproximación a partir del análisis de los núcleos. Werken 7: 39-58.

Cossa, N.

2019. Biología de la conservación de tres especies de cauquén (Chloephaga spp.). Tesis Doctoral inédita. Facultad de Cencias Exactas y Naturales, Universidad de Buenos Aires.

Cruz, I.

2015. Las investigaciones sobre preservación de huesos de aves y mamíferos grandes en Patagonia (Argentina). Archaeofauna 24: 209-224.

De Nigris, M. E.

2004. El consumo en grupos cazadores recolectores. Un ejemplo zooarqueológico de Patagonia meridional. Buenos Aires, Colección de Tesis Doctorales, Sociedad Argentina de Antropología.

2008. Modelos de transporte etnoarqueológicos: sobre su aplicabilidad y pertenencia para el interior de Patagonia. En A. Acosta, D. Loponte y L. Mucciolo (comps.), Temas de Arqueología: Estudios Tafonómicos y Zooarqueológicos (1): 37-55. Buenos Aires, Asociación amigos del Instituto Nacional de Antropología y Pensamiento Latinoamericano.

De Nigris, M. E. y G. Mengoni Goñalons

2004. El guanaco como fuente de carne y grasas en Patagonia. En M. T. Civalero, P. M. Fernández y A. G. Guráieb (eds.), Contra Viento y Marea. Arqueología de la Patagonia: 470-476. Buenos Aires, Instituto Nacional de Antropología y Pensamiento Latinoamericano.

Elkin, D.

1995. Volume density of South America camelids skeletal parts. International Journal of Osteoarchaeology 5: 29-37.

Emerson, A. M.

1993. The Role of Body Part Utility in Small-Scale hunting Under Two Strategies of carcass Recovery. En J. Hudson (ed.), From Bones to Behavior Ethnoarchaeological and Experimental Contributions to the Interpretation of Faunal Remains: 138-154. Southern Illinois, Center for Archaeological Investigations, University of Carbondale.

Enloe, J. G.

1993. Ethnoarchaeology of marrow cracking: implications for the recognition of prehistoric subsistence organization. En J. Hudson (ed.), From Bones to Behavior Ethnoarchaeological and Experimental Contributions to the Interpretation of Faunal Remains: 82-97. Southern Illinois, Center for Archaeological Investigations, University of Carbondale.

Espinosa, S., J. B. Belardi y F. Carballo Marina

2000-02. Fuentes de aprovisionamiento de materias primas líticas en el interfluvio Coyle-Gallegos (provincia de Santa Cruz). En Universidad Nacional de la Patagonia Austral (ed.), Desde el País de los Gigantes. Perspectivas arqueológicas en Patagonia I: 5-18. Río Gallegos.

2020. Puntas de proyectil líticas de la cuenca media e inferior del río Coyle (Santa Cruz): aportes al estudio del uso del espacio regional y a la distribución espacial del diseño Magallanes IV. Intersecciones en Antropología 21(2): 201-211. 
L. Stoessel y otros - Sitio Laguna Las Vegas: procesamiento y Consumo de GUanacos (LAMA Guanicoe)...

Fernández, $\mathrm{P}$

2010. Cazadores y presas 3500 años de interacción entre seres humanos y animales en el noroeste de Chubut. Buenos Aires, Fundación de Historia Natural Félix de Azara.

Franco, N. V., L. A. Borrero y G. F. Lucero

2019. Human Dispersal in the Atlantic Slope of Patagonia and the Role of Lithic Availability. Palaeoamerica. A Journal of early human migration and dispersal 5(1): 88-104.

Goñi, R. A.

2000. Arqueología de momentos históricos fuera de los centros de conquista y colonización: un análisis de caso en el sur de la Patagonia. En Universidad Nacional de la Patagonia Austral (ed.), Desde el País de los Gigantes. Perspectivas arqueológicas en Patagonia I: 283-296. Río Gallegos.

Gutiérrez, M.

2004. Análisis tafonómicos en el área Interserrana (Provincia de Buenos Aires). Tesis Doctoral inédita. Facultad de Ciencias Naturales y Museo, Universidad Nacional de La Plata, La Plata.

Hajduk, A. y M. J. Lezcano

2005. Un "nuevo-viejo" integrante del elenco de instrumentos óseos de patagonia: los machacadores óseos. Magallania 33(1): 63-80.

Hogg, A. G., T. J. Heaton, Q. Huan, J. G. Palmer, C. S. M. Turney, J. Southon, A. Bayliss, G. Blackwe Boswijk, C. Bronk Ramsey, C. Pearson, F. Petchey, P. Reimer, R. Reimer y L. Wacker 2020. SHCal20 Southern Hemisphere calibration, 0-55.000 years cal BP. Radiocarbon 62. Doi: 10.1017/ RDC.2020.59.

Hosfield, R.

2016. Walking in a Winter Wonderland? Current Anthropology 57(5): 653-682.

Johnson, E.

1985. Current Developments in Bone Technology. En M. B. Schiffer (ed.), Advances in Archeological Method and Theory, Volumen 8: 157-235. New York, Academic Press.

Kaufmann, C.

2009. Estructura de edady sexo en guanacos. Estudios actualísticos y arqueológicos en Pampa y Patagonia. Buenos Aires, Sociedad Argentina de Antropología.

Kaufmann, C. A., M. C. Álvarez, L.G. L’Heureux y M. A. Gutiérrez

2013. Dimorfismo sexual en la pelvis de Lama guanicoe (Artiodactyla, Camelidae): un caso de aplicación en el sitio Paso Otero 1, Buenos Aires, Argentina. Mastozoología Neotropical 20(1): 47-59.

Lupo, K. D.

2006. What Explains the Carcass Field Processing and Transport Decisions of Contemporary HunterGatherers? Measures of Economic Anatomy and Zooarchaeological Skeletal Part Representation. Journal of Archaeological Method and Theory 13(1): 19-66.

Lyman, R. L.

1991. Thaponomic Problems with Achaeological Analysis of Animal Carcass Utilization and Transport. Illinois State Museum Scientific Papers. Volumen 23.

2005. Analyzing cut marks: lesson from artiodactyl remains in the northwestern United States. Journal of Archaeological Science 30: 1722-1732.

Mancini, M. V., M. Paez, A. Prieto, S. Stutz, M. Tonello e I. Vilanova

2005. Mid-Holocene climatic variability reconstruction from pollen records ( $32^{\circ}-52^{\circ} \mathrm{S}$, Argentina). Quaternary International 132: 47-59. 
Matera, S., L. López, M. C. Pallo y N. A. Cirigliano 2019. Estudios de impacto e investigación arqueológica: una experiencia complementaria en Tapi Aike (sur de la provincia de Santa Cruz, Argentina). Práctica Arqueológica 2(2): 35-51.

Mazzoni, E. y M. Vázquez

2001. Evaluación de pastizales húmedos para un aprovechamiento sustentable en la cuenca del río Gallegos (Provincia de Santa Cruz, Argentina). VIII Encuentro Latinoamericano de Geógrafos: 175-182. 2004. Ecosistema de mallines y paisajes de la Patagonia Austral (Provincia de Santa Cruz). Ediciones INTA.

Mengoni Goñalons, G. L.

1996. La domesticación de los camélidos sudamericanos y su anatomía económica. En D. C. Elkin, C. M. Madero, G. L. Mengoni Goñalons, D. E. Olivera, M. C. Reigadas y H. D. Yacobaccio (eds.), Zooarqueología de camélidos 2: 33-45. Buenos Aires, Grupo Zooarqueología de Camélidos.

1999. Cazadores de guanaco de la Estepa Patagónica. Colección de Tesis Doctorales, Sociedad Argentina de Antropología.

Montalvo, C. I.

2002. Root traces in fosil bones from the Huayquerian (Late Miocene) faunal assemblage of Telén, La Pampa, Argentina. Acta Geológica Hispánica 37(1): 37-42.

Morín, E.

2007. Fat composition, skeletal part selection and Nunamiut decision-making. Journal of Archaeological Science 34: 69-82.

Muñoz, A. S.

1997. Explotación y procesamiento de ungulados en Patagonia Meridional y Tierra del Fuego. Anales del Instituto de la Patagonia 25: 201-222.

2001. El guanaco en la dieta de los cazadores-recolectores del norte de Tierra del Fuego. Análisis de dos casos procedentes del área Bahía Inútil-San Sebastián. En G. L. Mengoni Goñalons, D. E. Olivera y H. D. Yacobaccio (eds.), El uso de camélidos a través del tiempo: 155-178. Buenos Aires, Ediciones del Tridente.

Nuevo Delaunay, A., J. B. Belardi, F. Carballo Marina, M. J. Saletta y H. De Angelis

2017. The incorporation of glass and stoneware among Southern continental Patagonia and Fueguian hunter-gatherer from XVIII th to XX th century. Antiquity 91(359): 1330-1343.

O'Connell, J. F., K. Hawkes y N. Blurton Jones

1988. Hadza Hunting, Butchering, and Bone Transport and their Archaeological Implications. Journal of Anthropological Reserch 44(2): 113-161.

Oliva, G., L. González, P. Rial y E. Livraghi

2001. El ambiente en la Patagonia Austral. En P. Borrelli y G. Oliva (eds.), Ganadería ovina sustentable en la Patagonia Austral. Tecnología de Manejo Extensivo: 19-82. Buenos Aires, Ediciones Instituto Nacional de Tecnología Agropecuaria.

Olsen, S. y P. Shipman

1988. Surface Modification on Bone: Trampling versus Butchering. Journal of Archaeological Science 15: $535-553$

Orquera, L. A.

1987. Advances in the archaeology of the Pampa and Patagonia. Journal of World Archaeology 1 (4): 333-413. 
L. Stoessel y otros - Sitio Laguna Las Vegas: procesamiento y Consumo de GUanacos (LAMA Guanicoe)...

Outram, A. K.

2001. A new approach to identifying bone marrow and grease exploitation: why the "Indeterminate" fragments should not be ignored. Journal of Archaeological Science 28(4): 401-410.

Peláez, P. A. y N. L. Jiménez

2006. Los viajeros en el Coy. En J. B. Belardi, F. Carballo Marina y S. Espinosa (eds.), La cuenca del río Coyle: estado actual de las investigaciones: 129-164. Río Gallegos, Universidad Nacional de la Patagonia Austral.

Rindel, D. D.

2013. Marcos de referencia y frecuencia de partes esqueletarias de guanaco en sitios de Patagonia meridional: el caso del índice de médula insaturada. En A. Zangrando, R. Barberena, A. Gil, G. Neme, M. Giardina, L. Luna, C. Otaola, S. Paulides, L. Salgán y A. Tivoli (comps.), Tendencias teóricometodológicas y casos de estudio en la arqueología de la Patagonia: 515-522. San Rafael, Mendoza, Museo de Historia Natural.

Rindel, D., R. Goñi, J. B. Belardi y T. Bourlot

2017. Climatic Changes and Hunter-Gatherer Populations: Archaeozoological Trends in Southern Patagonia.

En G. G. Monks (ed.), Climate Change and Human Responses. A Zooarchaeological Perspective: 153-172. Holanda, Springer.

Santiago, F. C., N. Pal, M. C. Salemme, V. Bartoli y A. Lasa

2019. Use and forget: Contribution to the discussion about the bone tolos called "machacadores" (pounders), Patagonia, South America. Journal of Archaeological Science: Reports 28: 102012.

Stiner, M. C.

1991. Food Proccurement and Transport by Human and Non-human Predators. Journal of Archaeological Science 18: 455-482.

Stuiver, M., P. J. Reimer y R. W. Reimer

2021. CALIB 8.2 [www program] at http://calib.org.

Zolitschka, B., M. Fey, S. Janssen, N. I. Maidana, C. Mayr, S. Wulf, T. Haberzettl, H. Corbella, A. Lücke,

C. Ohlendorf y F. Schäbitz

2019. Southern Hemispheric Westerlies control sedimentary processes of Laguna Azul (south-eastern Patagonia, Argentina). Holocene 29(3): 403-420. 
